\title{
Preliminary Research on Basic Color Words in [Wa] Language
}

\author{
Zhixiang Xie \\ Communication School \\ Yunnan University of Finance and Economics \\ Kunming, China \\ xzxkm@163.com
}

\begin{abstract}
The Color Words is a common word category among each national language in the world, there are five core terms of basic color words in the Va [Wa] language: Black, white, red, green, yellow; The basic language words in Va [Wa] language can be divided into single color words and composite color words in terms of the structure. Basic color words in Va [Wa] language are monosyllabic words while synthetic color words mainly include compound color words and derivation. Va [Wa] people prefer black and red, cultural connotations are given to basic color words in Va [Wa] language by Wa people themselves.
\end{abstract}

Keywords: Va [Wa] language; color words; characteristic; cultural connotation

\section{INTRODUCTION}

The color words are the words used to record various colors of natural objects with man's linguistic symbols and to describe the visual perception brought by light waves emitted, reflected or transmitted by objects. Man's sensation about various colors existing in objective world could be common. Such as white snow, red blood, green field, blue oceans, colors like that are objective material Colors. The meanings of these color words are rational meanings of them, which is the base sense of a word. When it comes to people's subjective world, it can be reflected through language because different nations own different expressions and languages. There is a conclusion according to Brent Berlin and Paul Kay based on the research of more than 100 different languages: Color words exist in each language but the amounts are quite different." ${ }^{[1]}$ We think that the analysis and deep research on color words in national minorities will not only be an excellent cognitive material, but contribute to learn the nationally cultural characteristics and features of minorities' language."We mainly describe and research the color words of Yunnan Lincang Va [Wa] language (hereinafter referred to as the Wa language) from three aspects: distribution, structure characteristics, and cultural connotation of the color words.

\section{THE Distribution OF BASIC COLOR WORDS IN WA LANGUAGE}

"In terms of the distribution of color words, after the research on different languages, Berlin\&Kay (1969) think the distribution of basic color words in any language will accord with the following sequence: [white/black]>red $>$ [green/yellow] $>$ blue $>$ brown $>$ [purple/pink/orange/gray]. In native language, the color of the most typical color words is referred to as "basic color (focal color)", which will be the criterion for segmentation and classification of color continuum. Berlin\&Kay also believe that basic color words of various languages are in the range of this sequence and follow the left-to-right precedence sequence: The color words on the left do not necessarily have the right color words, and the right color words must have the color words on the left. ${ }^{[2]}$

Based on the study on color words in Wa language by predecessors and field work, we can ascertain the six basic colors in Wa language: black, red, white, yellow, green and blue. Wa language accords with Berlin\&Kay's sequence basically. In Wa language, glāi (green) includes "blue", "green" and "cyan" in Chinese, so we believe there are five basic color words in Wa language, the distribution is:

[black/white] > red > [green(blue)/yellow]

\section{The StRUCTURAL FeATURES OF COLOR WORDS IN WA LANGUAGE}

The color words in Wa language can be roughly divided into two types, monosyllabic color words and synthetic color words. It can be expressed as the picture below:

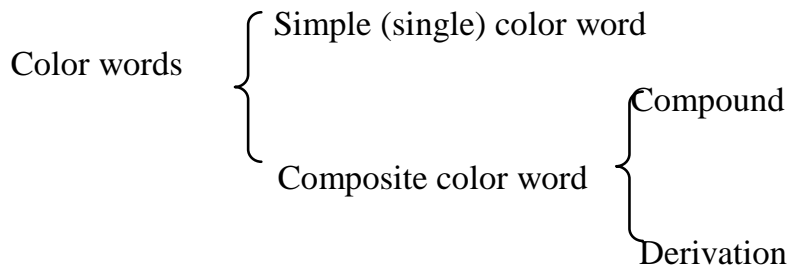

\section{A. Simple (single) Color Words}

Simple (single) color words are the most important and basic parts in color words, there are five kinds of single color words in Wa language according to the analysis above: White, black, red, green, yellow. 
TABLE I.

\begin{tabular}{|cccccc|}
\hline Chinese & white & black & red & green blue cyan & yellow \\
\hline Wa language & bāing & lūng & raoh & glāi & si mgraing \\
\hline
\end{tabular}

It can be seen from table I:

1) The basic color words in Wa language are expressed by monosyllabic words, while using these monosyllabic words, other linguistic root will be added to constitute disyllabic words, for example: watermelon red - raoh rod, earth red - raoh diex. It shows the main features of words in Wa language, from the perspective of the composition of words, the root of monosyllables are the basis of the vocabulary of Wa language. Its compound words have similar structural forms to Chinese and many other minority languages in southern China.

2) The word "glāi" means "blue, green, cyan" in Wa language, which shows the common part among many minority languages in Southern China. For instance, in Miao language (the Miao nationality distributed partly in Qiandong, Guizhou),"nox" includes "green, cyan and blue" of Chinese. In the branches of $\mathrm{Yi}$ language (the $\mathrm{Yi}$ nationality distributed over Yunnan,---Sichuan and Guizhou),"cyan" equals "blue, green" in most case, which is the same in Lisu language (the Lisu nationality distributed in Yunnan). "Cyan" and "black" could be almost the same meaning in Hani (living in Yunnan) and Laku (living in Southwest of Yunnan) language. It is because that color words, which owns strong ambiguity, is typical vague terms. As Louis Hjelmslev said: "each language determines the boundaries of the language (color words) randomly in the spectrum."[3]

When these single color words are used to modify specific issues, these color words would be put before them. To take "clothes" for an example:

TABLE II.

Chinese clothes white clothes black clothes red clothes blue clothes

Wa language si nbeix si nbeix bāing si nbeix lūng si nbeix raoh si nbeix glāi

\section{B. Composite Color Words}

Composite color words are which exist in addition to single color words. In the study of Kay Paul\& Mike Daniel, black, white, red, orange, yellow, brown, green and purple are called basic color words; others are not or derived ones. The derived color words in Wa language mainly include composite color words and derived color words.

1) Compound color words. In terms of quantity, compound color words are the main constituent members of the color words in Wa language. It can be divided into the following categories according to the nature of morpheme and the relationship between morphemes.

a) color morpheme + degree + raoh blū blīex - light red, lūng suah-jet black, bāing da - pale, bāing glāi - light blue, bāing lag - silver white, bāing lōuig - pure white, si mgraing bae - dark yellow si mgraing blīex - light yellow, glāi blū blīex - light green, glāi hlaxkaox - emerald green, bāing on soft white

The post-increment component of these color words restricts the degree of color morpheme.

b) color morpheme + color morpheme. raoh bāing pink, ngūd lūng- dark purple(purple black), bāing bae - light gray (gray white), bāing glāi- light blue, ūng bae - dark gray(black gray), glāi bae - celadon(willow-green), glāi bāing- light green/light blue, glāi lūng - dark green

The quantity of this kind of color words will not be small in different languages.Kay Paul and McDaniel draw graphs of basic color words and point out that only a narrow segment of the spectral wavelength around 510 nanometers is pure green, and the spectral wavelength is a narrow segment around 575 nanometers. Is pure yellow, between the two is either green with yellow, or yellow with green, the same reason, There is also a long transition between green and blue, can be called geue (green blue). The word is composed of two words: green (blue) and blue (blue). There are also many compound color words in Wa language. For example: the color "pink" is between red and white in the spectrum, raoh bāing is used to record that in Wa language. It is compounded by two roots roah(red) and bāing (white). There is another example:the color "purple black" is between cyan and black in the spectrum, ngūd lūng is used to record that in Wa language, which is compounded by two roots ngūd (cyan) and lūng (black).

c) Color morpheme + Object morpheme.

Glāi(blue) rāo ma(sky) azure-glāi hlax oux-lawngreen Raoh(red) diex(earth) earth red-raoh dāi dīe-peachblow raoh rod-watermelon red.

Such color words use the colors of common things to represent the kind of colors.Color morpheme + Object morpheme

The composition of the color words is an open category, there are many variants in the expression of Chinese colors (geographic variants or personal variants), so some people call such color words as "usual color names."In this kind of color words in Wa language, the "object morphemes" added later are mostly morphemes such as plant colors, animal colors, and natural colors.

2) Derived color words. There is another kind of distinctive color words in Wa language, which is recorded by the "simple color words" are rooted in the form of partial overlapping, additional affixes and repeated affixes,. overlapping roots, and additional affixes.

raoh raoh ngei- red lūng lūng ngei -black

glāi si im-shiny green glāi si ngī-lush green

lūng li li-pitch black

bāing jōd jōd -sheer white bāing nyū nyū -white

bāing si lōg -shining white

bāing si ngī - bright and shining

raoh reeig reeig-brilliant red raoh si ngī-shiny and bright red raoh si ngōb- rouge 
Such color words are represented by the color of the appearance of a certain color, followed by overlapping components or add affixes, mainly to explain or limit the root degree.

\section{Cultural Connotation of Basic COlor Words IN WA LANGUAGE}

The Wa nationality is a minority with long history, in the Zhou and Qin in the Tang Dynasty that the historical trajectories of the Qiang ancestors were recorded in detail. Wa language belong to the South Asian language Bangladesh language group. About the characteristics of Wa language, Wang jingliu made a summary that Wa language, whether their phonetic structures or vocabulary or grammar, are at least topologically very similar to Chinese in our country and other minority languages in the South after research. Therefore, the number and the way of word formation of the basic color words in Wa language are basically the same as those of many minorities in the South such as Lisu, Yi, and Miao language. However, the color words reflect only the objective spectrum. When the color words are used in different societies, they will be cultured in the origins of various ethnic cultures and marked with the national mentality. In history, it has been endowed with different cultural meaning, so the same color would have different meanings and symbols in different nationalities and different languages.

Black and red have always been their favorite colors since the history of the development of the Wa people. There is a saying in Bai Yi Zhuan written by Qian Guxun," Ha la (the ancient salutation of Wa people in Ming dynasty), both men and women owe pitch-black hair. The man wears a veil of cloth as well as imitating Baiyi people. Woman rolls up the hair on the back of head and with a variegated beads necklace, wearing the costume made of Suoluo cloth (Chinese cotton, thick fabric) and decorated with some rattan, wearing no shoes." "Gu la people are all black. Ha la, Gu la is the ancient salutation of Wa people in Ming dynasty," ${ }^{[4]} \mathrm{Ha}$ la people only have no family names but given names, usually wear black costume, with similar living habits as Puman nationality( an ancient minority in Yunnan) but more gentle and soft in terms as personality. In the traditional costumes of the Wa people, both men and women are black: Their clothes, trousers, and skirts are black, as well as their headband and the foot-binding cloth. Women wear a black lacquer on the neck, waist, hands and feet as an ornament in order to be beautiful. This black-beauty tradition can also be seen in the modern "When-You-Black" festival of large-scale tourism and cultural events in Cang Lan, Yunnan province. Whoever is the darkest is the most beautiful. There are quite a few Va's folk songs taking black for beauty, such as "Va girls like black pearl,"'Va girls are black roses", "black hair delimits so beautiful", Va girls pitch-black long hair" and so on. In addition to those, Wa people used to have habits called" black teeth", women there take black teeth for beauty. During Lunar August women will pick a special fruit (Chinese fevervine, a kind of herbs), their teeth will become black and bright after chewing. Therefore, in the oral literature of the Wa nationality, "tooth black" still means beauty till now. There is idiom up to now saying: Black teeth, pretty appearance. Walking together in similar rhythm and smiling to each other. They also use the black earth to describe their hometown, such as the folk songs of Wa people:" While grabbing and staring at the black earth, father and mother's love come to our mind". The "black soil" here refers to the place where Wa people is nurtured. Wa people advocating blacks may be related to the living environment and customs they live in. As what Chen Guoqin has said" since ancient times, Wa people have been engaged in physical labor. In the long-term work, wind, sun, and rain have trained their strong physical and tenacious will. At the same time, they have also gave them dark bright skin and eyes, and even formed their admiration and worship of black. The Wa people love black because they respect hard work, courage and sincerity; Wa people respect the black because black symbolizes health, solemnity, and solemnity. This may be a major feature of the Wa people in their aesthetic sense.

Colors in the Wa people's life is relatively simple, they prefer dark and warm colors. In addition to black, their favorite is red. It is embodied in their costumes and utensils whose patterns are mostly black red lines; The traditional bag and old skirt are black and embellished with red. In the modifier language of the Wa nationality, red and black are often used together symmetrically. For example, there are such words in the greetings of hunting: The black squirrel came to the gimmick, and the red squirrel came to the tip of the arrow, and when described the dignified majesty of the official family they'd say: sits on black mat and stands on red carpet". In addition, they use the "black bamboo tube, red gourd" as metaphor to "blue blood family" - it is said people come out of the "bamboo tube" and "calabash." Therefore, the "black bamboo tube" and the "red gourd" can be used to mean extraordinary birth .In the folk songs of the Wa people, they also showed the Wa people's preference of red. They often used the words "cherry blossom" and "pomegranate flower" as a metaphor for a girl, and used "a bunch of red flowers" to describe the "handsome young man". When the girl said that she was still young, she would say "The color of the hen's coat has not yet turned red."When describing a handsome man, the commonly used modifier is "wearing a gun and red calabash (have gunpowder in)."

The reason why the Wa people like red is that they may have a strong preference and esteem for fire. The fire is indispensable in the Wa nationality's life. "Slash and burn" is on the fire, cooking on the fire, preventing the cold by fire, and smoking - the Va ethnic group smokes whether he is men, women, or children; which must depend on fire as well. In the Wa people's home, the fire in the fire pit is immortal for many years. In the idiom, "stand to meet blossom of firewood and sit down until the fire stick grow fruit ", meaning that it is a long time to stay beside the fire pit. Wa people welcome guests to chat by the fireside next to the fire pit."Three feet 
empty, fire pit chilly" means home breaks. The custom of the "New Fire Festival" of the Wa nationality is an typical example. The "New Fire Festival" of the Wa nationality is based on the village as a unit, in the annual lunar calendar in May and June. The Wa people worship the fire and believe that the fire is a necessary factor for the formation of the world. In the past, in order to keep fire burning, every family of Wa nationality had to take a fire ceremony. They put out the old fire in the fire pit, regained a new fire, and obtained a new fire. After that, families will save the fire and do not let it put out. Fire pits play an important role while preserving the fire. Therefore, in the fire pit of the Wa nationality, the fire always flutters with a thick whole chestnut surrounding in the fire pit so that the fire will not go out. Because of this, in the Wa language, there is "where there is clear water, there is the family of Dai; where there is fiery, there is Va's mountain"。 Water has become a symbol of Dai villages; The fire became synonymous with the residence of Wa nationality.

The Wa people strongly praise and favor black and red, but they are rather disgusted with white. In Wa language, they use many words and actions to depreciate the white. An idiom in Wa language said "white teeth chew well, fluffy hair sweep floor well", This saying is that this tooth is vain, to ridicule women as being ugly, because the Wa people used to take black for beauty, the same as their teeth. There is a saying of the Wa people: the dry land is wide, the woman is lazy. To depreciate women with white and tender skin, their intention is mainly to contrast the appreciation of women with darker skin. Therefore there is a sentence "nblēih nbun bāing,,roung mōh sang yāoy yō nbun lūng heui" in Va's culture, which means to depreciate female with sheer white skin is to appreciate those with dark skins. There are such lyrics in the singing, dancing, and playing tune that the young female love. I don't like to wear white clothes. I love to wear dark black clothes. I don't love flowers in white. I love purple poppies, etc. These lyrics also clearly show their disgrace for white and their preference for black. Even white flowers they only like flowers that have red, purple, yellow, or other color stamens rather than pure white. Guests will receive a good reception in Wa people's family, in addition to drink selfmade wine, they would make chicken porridge but prevent chicken with white feather. They'd think it's impolite to serve guests by chicken with white feather, It would mean diminish to their guests. There is another way of saying that killing the white pheasant to serve guest will make him never come again. The Wa people's distrust of white can be seen from that, but also show their straight and sincere.

Colors like cyan, green, blue, and yellow are often used to describe the color characteristics of various things in slang, making the depicted objects more realistic and vivid. For example: As lyrics of the song come and visit Wa mountain said:" Red silk cotton flowers covering the mountain as fire, lush bamboo shaking in the wind, green mountain and clear water are greeting guests. In mōh man si mgraing this is yellow cloth", Wa's idiom "niab dix blah nblie ong, blah hleng blah glai; yah dix gia kuan būi,lāi daix lāi jāong."The yellow and green bamboo fur leaves are folded as a bee mark, the handle and foot pattern are untied and viewed. As for these basic color words, in the expression of people's emotions and opinions on things in the Wa nationality, due to the limitations of the materials, there is no conclusion in this aspect currently.

As what is mentioned in the review, color words are a vocabulary category in all national languages of the world. Due to the different living conditions, ethnic history, religious beliefs, and different thinking ways of various ethnic groups, their value orientation towards cultural connotations and color words are different. As Humboldt discussed the interrelationship between language and ethnicity in his book "On the Differences of Human Language Structure and Its Impact on the Development of Human Spirit" ${ }^{[5]}$, it states that "Language seems to be the external manifestation of national spirit; The language of the nation is the spirit of the nation, and the spirit of the nation is the language of the nation.

\section{ACKNOWLEDGMENT}

We would like to express our gratitude to all those who helped me during the writing of this thesis. This research paper was partially supported by Communication School, Yunnan University of Finance and Economics. Also as phased achievement, it is sponsored by National Social Science Project, Comparative Research on Investigation into Yunnan Dialect of Thai Mandarin (16BYY048). We thank our colleagues from Communication School who provided insight and expertise that greatly assisted the research.

We would also like to show our gratitude to the moderators for sharing their pearls of wisdom with us during the course of this research. And we are also immensely grateful to reviewers for their comments on an earlier version of the manuscript. In addition, we would also thank peer reviewer for comments that greatly improved the manuscript.

Last, but not least, we recognize that this research would not have been possible without the financial assistance of the University of Finance and Economics, and other institutions, and express my gratitude to those agencies.

\section{REFERENCES}

[1] A Comparative Study of Manchu-Tunguss Language and Related Languages [C], Zhao a'ping,Beijing: Nationalities Publishing House, 2008:117.

[2] Luo TianhuaThe distribution of color words [J] Minority Language of China, 2009(6):28-30.

[3] Transmutation from Wu Tieping.Fuzzy Linguistics [M].Shanghai: Shanghai Foreign Language Education Press, 1999:274.

[4] (Ming dynasty) written by Qian Guxun, checked and annotated by Jiang Yingliang .Collation and annotation of Bai Yi Zhuan[M]. Kunming:Yunnan People's Publishing House, 1980:99.

[5] The Differences of Human Language Structure and Its Influence on the Development of Human Spirit[M]. [German]Humboldt. Beijing: Commercial Press,2002:52. 